\title{
The impact of heavy vehicle's composition to traffic performance of Jakarta Intra Urban Toll Road (JIUT) in macroscopic level
}

\author{
Nahry Yusuf $^{1}$, and Ismi Dilianda Wulandari ${ }^{*}$ \\ ${ }^{1}$ Department of Civil Engineering, Universitas Indonesia, Depok, 16424, Indonesia
}

\begin{abstract}
Freight vehicle access restriction policy in 2011 has had an impact on the performance of Jakarta Intra Urban Toll way (JIUT) system. The statutory segment (Cawang-Tomang) of this toll road system seems to have better performance, but not for the advisory segment (Cawang Ancol). Basically, heavy vehicles (HV) shift their routes to the advisory segment to avoid the statutory segment at which they are prohibited to access from 05.00 a.m. to 10.00 p.m.. This study aims to investigate the impact of the HV composition on the traffic performance of the advisory segment of JIUT. Data were obtained from 48 hours of traffic recording at a part of Cawang-Ancol segment. It was found that the Underwood Model (exponential model) can represent the relationship between the three main parameters of traffic flow on the advisory segment, i.e. volume, speed, and density. Based on the developed traffic flow models which are classified on the HV composition, it is shown that the free flow speed $\left(\mathrm{u}_{\mathrm{f}}\right)$ for HV composition $\leq 6 \%$ (i.e. $144.91 \mathrm{~km} / \mathrm{h}$ ) is higher $35.41 \%$ than the one of $\mathrm{HV}$ $>6 \%$ (i.e. $107.02 \mathrm{~km} / \mathrm{h}$ ). The actual road capacity ( $\mathrm{q}_{\mathrm{m}}$ ) in HV composition $\leq 6 \%$ (i.e. $4442 \mathrm{pcu} /$ hour) also higher $12.83 \%$ than the one of $\mathrm{HV}>6 \%$ (i.e. $3937 \mathrm{pcu} /$ hour). The results will benefit to the transport authority to justify the truck access restriction implementation.
\end{abstract}

\section{Introduction}

The toll road is part of the urban road system that is aimed to reduce traffic congestion in dense areas such as Jabodetabek (Jakarta-Bogor-Tangerang-Bekasi), Indonesia. Indonesia Statistic Bureau stated that the population of cars, buses, and freight vehicles passing through Jakarta toll road reached 21.2 million units in 2014 and will continue to grow. On the other hand, the toll road was claimed to increase the cost efficiency of logistics transportation. The global market research conducted by Frost \& Sullivan [1] stated that Indonesian transportation and logistics growth would reach $15.4 \%$ in 2020 .

Trucks are classified as heavy vehicles, and they are the most widely used in logistics activities due to its flexibility, low-cost, and relatively higher speed for shorter distances under normal infrastructure conditions [2]. However, the large number of heavy vehicles has a negative impact on the performance of traffic flow [3]. First, the average space taken

\footnotetext{
*Corresponding author: ismidilianda@gmail.com
} 
is higher than regular passenger cars. Second, its operational characteristics, such as speed, acceleration, deceleration, and maneuverability are slower compared to regular passenger cars $[4,5]$. Mixed vehicles with different operating capabilities will produce various speeds.

Jakarta Intra Urban Toll Road (JIUT) system circles the inner part of Jakarta and connecting Cawang-Pluit in two routes, those are Ancol route and Tomang route (Fig. 1). Access restriction on JIUT was performed in June 2011. It is regulated in Regulation of Indonesia Minister of Transportation No. 62, 2011 about the operational time of freight vehicles of 1.2 axle configuration or more in JIUT. Freight vehicles, but fuel-carry vehicles, are not allowed to pass Cawang-Tomang-Puit segment (as a statutory segment) during 5.00 a.m. to 10.00 p.m.. As an impact, the section that became an alternative to the movement of freight vehicles at the time of such restrictions was the Cawang-Ancol-Pluit segment. This segment is named as an advisory segment to indicate the transport authority provides this segment as an alternative segment and advice the freight vehicles to use it to substitute the restricted section. The trip route furtherly discussed is Cawang-Ancol-Pluit.

Research on the traffic flow on the macroscopic and microscopic level has been primarily done to show the traffic condition and vehicle characteristics at a certain point or segment. Recent studies on the modeling and simulation of traffic flows are continually evolving to obtain accurate and representative modeling [6]. The macroscopic review looks at the traffic flow that occurs in a group of vehicles globally or the whole road segment. It is only a little that discusses the existence of heavy vehicles in traffic flow at JIUT from the macroscopic point of view, particularly at its advisory segment. Hence, this study was aimed to investigate the impact of the HV composition on the traffic performance of the advisory segment of JIUT. This paper will discuss the research methodology in Section 2, Section 3 will explain the result and discussion, and Section 4 will be for the conclusion.

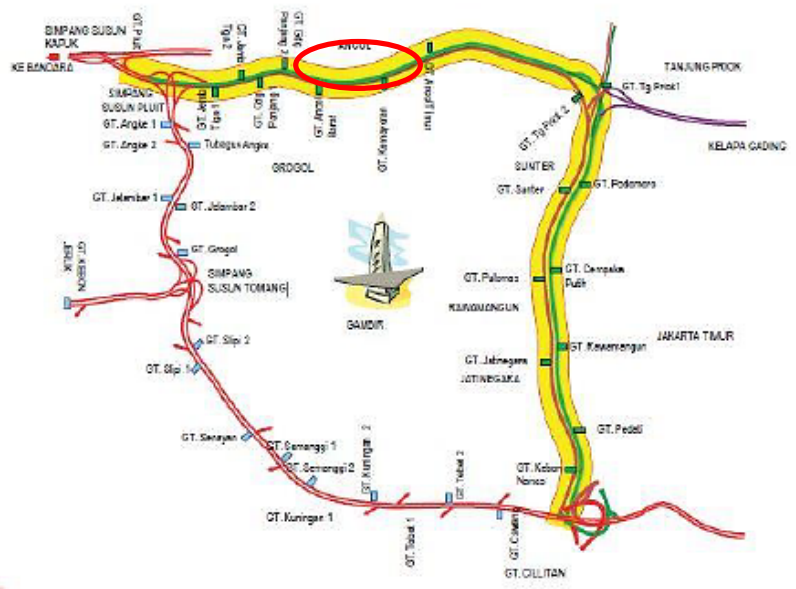

Fig. 1. Jakarta Inter-Urban Toll Road (JIUT) Ancol segment.

\section{Research methodology}

Referred to [7], in this research a video-based approach was taken to detect more traffic conditions and facilitate the collecting of existing traffic data visually. The information was collected through 24-hour data recording on $75 \mathrm{~m}$ length of Cawang-Ancol-Pluit segment. It is 3-lanes road without shoulder with $0 \%$ of road gradient, no access or exit ramp, and located in the tangent segment of its horizontal alignment. The camera was placed on the 6th floor of a high rise building that facing the observation segment (Fig. 2). This point was 
selected to observe the vehicle movements. The segment under consideration represented the entire actual traffic conditions, including free-flow and congestion-flow conditions.

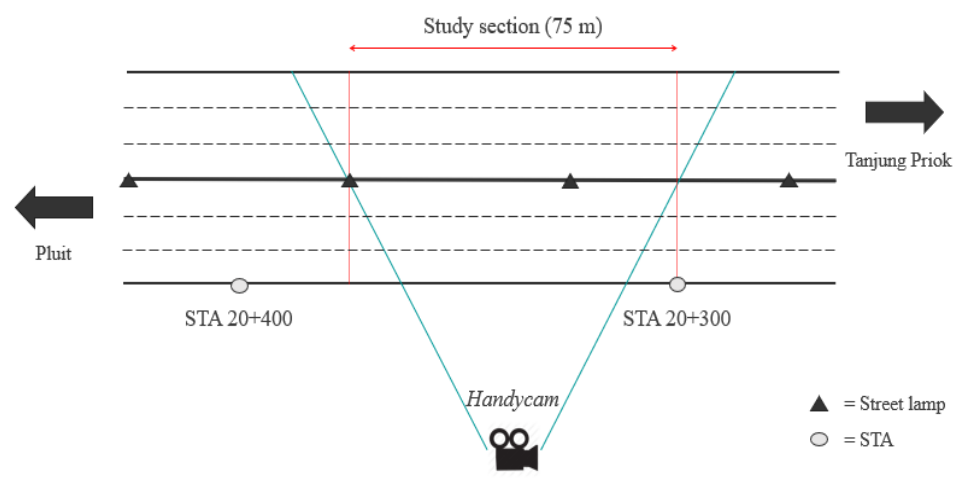

Fig. 2. Sketch of research data retrieval.

In the observation, the vehicles are classified into two groups, namely Heavy Vehicle (HV) and Non-Heavy Vehicle (Non-HV). HV was denoted by Large Bus (LB) and Large Truck (LT), while Non-HV for Light Vehicle (LV) and Medium Heavy Vehicle (MHV). The time and space of movement of any vehicles that crossed a predetermined road segment were observed in 5-minute time slices. Hence, there would be almost 288 data. Each data was classified into a certain group of the percentage of HV ( $\%$ of HV). The data that has been collected is then processed using Microsoft Excel worksheets to obtain three main characteristics of the macroscopic traffic stream, i.e., density, speed, and flow rate [8].

Furthermore, the traffic flow model calibration was developed using a regression technique by two approaches to representing the relationships among traffic stream characteristics. The first approach was a single-regime of two traffic variables, namely the relationship between speed and density or volume and speed. Greenshields et al. (1935) stated a linear form for the relation of speed-density on uninterrupted traffic flow, then a parabolic function of flow-density and speed-flow proposed lately by himself. A few years later, Greenberg (1959) used the logarithmic function, and Underwood (1961) used an exponential function to describe the relationship between speed-density [8]. The second approach was multi-regime that consider two variables with two or more advanced functions, and each represents different traffic conditions including free-flow and congested-flow situations. Since the data were grouped based on the $\%$ of HV, then the developed model was also grouped based on the \% of HV in the traffic stream to represent the HV composition in the entire traffic flow. The best representative model was chosen through the validation test on the observation data that is not included in the calibration process.

Finally, the effect of $\mathrm{HV}$ composition was investigated by comparing the traffic flow model of each group of $\%$ of $\mathrm{HV}$.

\section{Results and discussion}

\subsection{Speed - density characteristics}

Fig. 3 shows the trend of the speed of $\mathrm{HV}$ and non-HV, as well as the traffic density during the time of observation. Based on the pattern of the traffic flow, the period of observation was divided into three groups, namely $15.05-21.35$ p.m., 21.35 p.m. to 08.10 a.m., 08.10 
a.m. to 15.00 p.m.. Based on the correlation test of $\alpha=0.05$, it shows that the traffic density affects the vehicle speed, where the speed of both types of vehicles will increase as traffic density decreases. The figure also indicates that the HV speed is smaller than the Non-HV speed. During the high traffic density (15.05 p.m. to 21.35 p.m. and 08.10 a.m. to 15.00 p.m.), the difference between HV speed and Non-HV speed (around $4 \mathrm{~km} / \mathrm{hour}$ ) was not significant compared to the ones of the low-density condition. It is due to the more limited space for movement or speed acceleration. The speed difference between the two is quite significant in low density (i.e., around $41 \mathrm{~km} / \mathrm{hour}$ ). Table 1 indicates the comparison of average speed and standard deviation of $\mathrm{HV}$ and Non-HV.

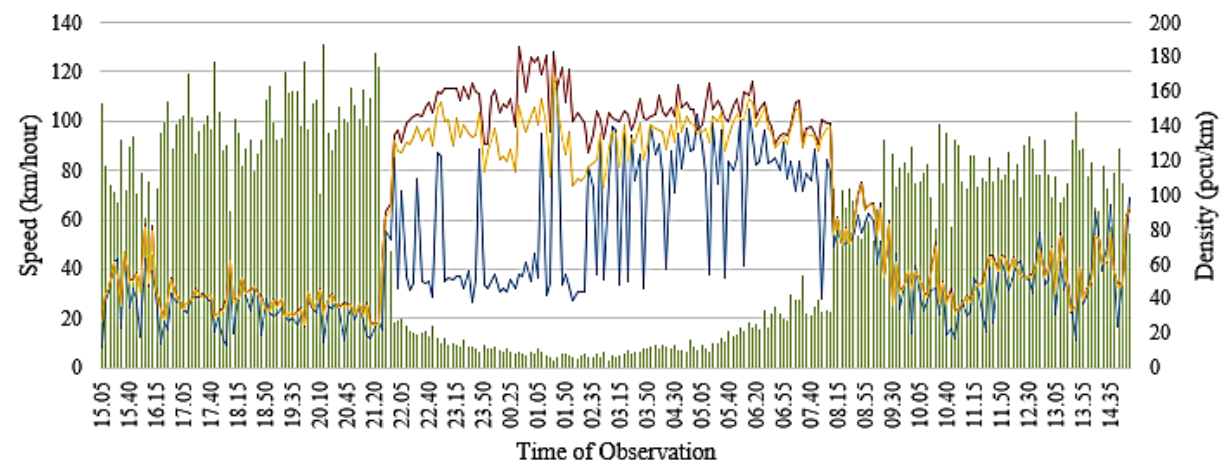

Density $\longrightarrow$ Speed of HV $\longrightarrow$ Speed of Non-HV $\quad$ Average Speed

Fig. 3. Time Series of speed and density.

Table 1. Average Speed of heavy vehicle and non-heavy vehicle

\begin{tabular}{|c|c|c|c|c|c|}
\hline \multirow[b]{2}{*}{$\begin{array}{c}\text { Period of } \\
\text { observation }\end{array}$} & \multicolumn{2}{|c|}{ Heavy Vehicle } & \multicolumn{2}{|c|}{ Non Heavy Vehicle } & \multirow{2}{*}{$\begin{array}{c}\text { Average } \\
\text { Difference } \\
\text { between HV } \\
\text { speed and Non- } \\
\text { HV speed } \\
\text { (km/hour) }\end{array}$} \\
\hline & $\begin{array}{c}\text { Average } \\
\text { speed } \\
\text { (km/hour) }\end{array}$ & $\begin{array}{l}\text { Standard } \\
\text { Deviation } \\
(\mathrm{km} / \mathrm{hour})\end{array}$ & $\begin{array}{c}\text { Average } \\
\text { speed } \\
\text { (km/hour) }\end{array}$ & $\begin{array}{l}\text { Standard } \\
\text { Deviation } \\
\text { (km/hour) }\end{array}$ & \\
\hline $15.05-21.35$ & 24.21 & 8.70 & 28.72 & 7.81 & 4.51 \\
\hline $21.35-08.10$ & 62.61 & 27.24 & 103.94 & 11.58 & 41.33 \\
\hline $08.10-15.00$ & 37.71 & 14.06 & 42.16 & 12.61 & 4.45 \\
\hline Entire day & 44.94 & 25.89 & 65.55 & 36.02 & 20.61 \\
\hline
\end{tabular}

\subsection{Volume, speed and density relationship}

Fig. 4a-4c shows the distribution of the entire data (265 of valid data) that shows the relationship among the three variables, namely volume, speed, and traffic density, and Table 2 shows their mathematical model. These models are not grouped according to \% of $\mathrm{HV}$ yet. Based on the regression technique, it is found that the best fit model is the Exponential Model. Using the Pearson correlation coefficients that are ranging from 0.7430.949 and $p$-values $<0.0001$, it is indicated that the selected model can represent the data well. 


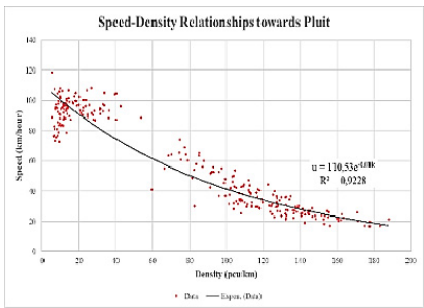

Fig. 4a. Speed-density relationships.

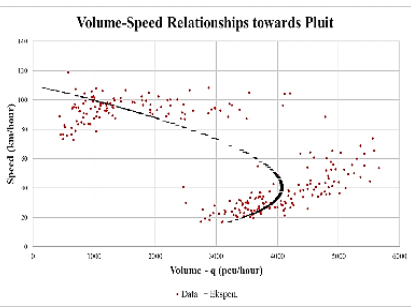

Fig. 4b. Volume-speed relationships.

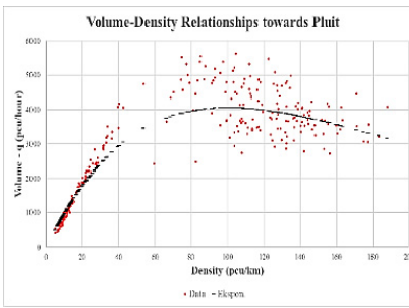

Fig. 4c. Volume-density relationships.

Table 2. Speed-flow-density relationship model.

\begin{tabular}{|c|c|c|c|}
\hline & Speed (u) - Density (k) & Volume (q) - Speed (u) & Volume (q) - Density (k) \\
\hline \multirow{2}{*}{ Equations } & $u=110,53 e^{-0,01 k}$ & $q=-100 u \ln \left(\frac{u}{110,53}\right)$ & $q=110,53 k e^{-0,01 k}$ \\
\hline $\mathrm{R}^{2}$ & 0.9228 & 0.5541 & 0.8659 \\
\hline
\end{tabular}

\subsection{The effect of heavy vehicle composition}

Based on the trial and error process to find the threshold number of $\%$ of $\mathrm{HV}$, " $\leq 6 \%$ of $\mathrm{HV}$ " and "> $6 \%$ of HV" were the best figure of $\%$ of HV that could distinguish well the traffic performance based on the HV composition. Other than those figures, the difference of the traffic performance was not quite significant and could not be investigated well. Hence, the effect of $\mathrm{HV}$ composition ( $\%$ of $\mathrm{HV}$ ) on traffic performance was investigated by comparing the traffic flow model of " $\leq 6 \%$ of HV" and the one of " $>6 \%$ of $\mathrm{HV}$ ".

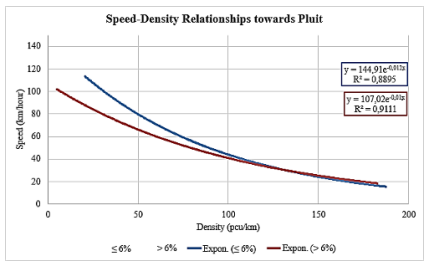

Fig. 5a. Speed-density relationships for $\% \mathrm{HV}$.

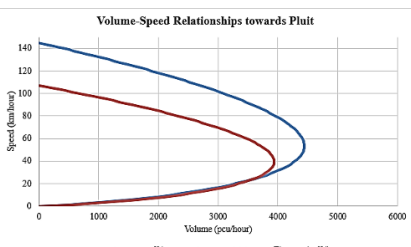

Fig. 5b. Volume-speed relationships for $\% \mathrm{HV}$.

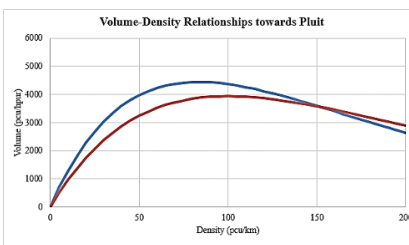

Fig. 5c. Volume-density relationships for $\% \mathrm{HV}$.

Table 3. Volume, density, and speed relationship towards Pluit.

\begin{tabular}{|c|c|c|c|}
\hline $\begin{array}{c}\text { \% of } \\
\text { HV }\end{array}$ & Speed-Density Relationship & $\begin{array}{c}\text { Volume-Speed } \\
\text { Relationship }\end{array}$ & $\begin{array}{c}\text { Volume-Density } \\
\text { Relationship }\end{array}$ \\
\hline$<6 \%$ & $u=144,91 e^{-0,012 x}$ & $q=-83,33 \mathrm{u} \ln \left(\frac{u}{153,24}\right)$ & $q=144,91 k e^{-0,012 x}$ \\
\hline$>6 \%$ & $u=107,02 e^{-0,01 x}$ & $q=-100 \mathrm{u} \ln \left(\frac{u}{107,02}\right)$ & $q=107,02 k e^{-0,01 x}$ \\
\hline
\end{tabular}


Each of Fig. 5a-5c and Table 3 show the two set of models, namely model of " $\leq 6 \%$ of $H V$ " and the one of " $>6 \%$ of HV". Fig. 5a shows that the composition of $\mathrm{HV}<6 \%$ has a better speed performance than HV $>6 \%$. The speed difference between the two groups is directly proportional to the density, where the speed difference will be close to zero when the traffic density is very high. The free flow speed of $\mathrm{HV} \leq 6 \%$ is $35.41 \%$ higher than the one of $\mathrm{HV}>6 \%$, while the road capacity of $\mathrm{HV} \leq 6 \%$ is $12.83 \%$ higher than the one of HV $>6 \%$ so that the road segment can accommodate more vehicles and has better speed. The speed-volume relationship shows nearly the same pattern at the congestion condition, but the trend of the two groups starts to change when the traffic becomes smooth.

Table 4 indicates the important parameters of traffic flow that are generated from those models, i.e., maximum flow (qm), free flow speed ( $\mathrm{uf}$ ), density on maximum flow ( $\mathrm{km}$ ), and speed on maximum flow (um). The free flow speed of $\mathrm{HV} \leq 6 \%$ (i.e. $144.91 \mathrm{~km} / \mathrm{h}$ ) is higher $35.41 \%$ than the one of $\mathrm{HV}>6 \%$ (i.e. $107.02 \mathrm{~km} / \mathrm{h}$ ). The actual road capacity of $\mathrm{HV}$ $\leq 6 \%$ (i.e. $4442 \mathrm{pcu} /$ hour) is $12.83 \%$ larger than the one of $\mathrm{HV}>6 \%$ (i.e. $3937 \mathrm{pcu} /$ hour).

Table 4. Parameter of traffic flow model to Pluit.

\begin{tabular}{|c|c|c|c|c|c|}
\hline \multirow{2}{*}{ Parameters } & \multicolumn{2}{|c|}{ Composition of $\mathrm{HV}$} & \multirow{2}{*}{$\begin{array}{c}\text { Value } \\
\text { difference }\end{array}$} & \multirow{2}{*}{$\begin{array}{c}\% \\
\text { difference }\end{array}$} & \multirow{2}{*}{ Unit } \\
\hline & $\leq 6 \%$ & $>6 \%$ & & & \\
\hline $\mathrm{q}_{\mathrm{m}}$ & 4442 & 3937 & 505 & 12.83 & pcu/hour \\
\hline$u_{f}$ & 144.91 & 107.02 & 37.89 & 35.41 & $\mathrm{~km} /$ hour \\
\hline $\mathrm{k}_{\mathrm{m}}$ & 83.33 & 100.00 & 16.67 & 20.00 & $\mathrm{pcu} / \mathrm{km}$ \\
\hline $\mathrm{u}_{\mathrm{m}}$ & 11.00 & 22.70 & 11.70 & 0.52 & $\mathrm{~km} /$ hour \\
\hline $\mathrm{R}^{2}$ & 0.8895 & 0.9110 & & & \\
\hline
\end{tabular}

\section{Conclusions}

This study investigated the effect of HV composition on the performance of traffic flows in the case of JIUT. It is concluded that heavy vehicle composition influences the traffic flow performance significantly with $6 \%$ of $\mathrm{HV}$ as a threshold. It was found that the percentage of $\mathrm{HV} \leq 6 \%$ had better performance than the one with $\mathrm{HV}>6 \%$. In high traffic density, the difference between HV speed, and Non-HV speed (around $4 \mathrm{~km} / \mathrm{hour}$ ) was not significant compared to the one of lower density condition. It is due to the more limited space for movement or speed acceleration. The speed difference between the two is quite significant in low density (i.e. around $41 \mathrm{~km} /$ hour).

This research is supported by research funds made available through the Research Scheme of Indexed International Publication for Student Final Project of Universitas Indonesia 2018 (Hibah PITTA 2018).

\section{References}

1. Frost \& Sullivan, Indonesia transportation and logistics industry continued economic growth momentum supports transport infrastructure investment and development. At: https://www.prnewswire.com/news-releases/indonesia-transportation-and-logisticsindustry-continued-economic-growth-momentum-supports-transport-infrastructureinvestment-and-development-300230259.html (2016) 
2. A. Yunani, Pelajaran dari seminar pengangkutan barang dengan truk atau kereta api? Aston Primera Pasteur Bandung sabtu 23 agustus 2014, At: https://www.linkedin.com/pulse/20140824154839-74768789-pelajaran-dari-seminarpengangkutan-barang-dengan-truk-atau-kereta-api-aston-primera-pasteur-bandungsabtu-23-agustus-2014 (2014)

3. C.G. Roh, B.J. Park, J. Kim, J. Transp. Eng. (2017)

4. F.D. Hobbs, Perencanaan dan teknik lalu-lintas (Gadjah Mada University Press, Yogyakarta, 1995)

5. K. Jain, S.S. Jain, M. Singh, Transportation Research Procedia 17, 468 (2014)

6. R. Mardiati, Jurnal ISTEK 8, 2 (2014)

7. M. M. El Sherief, I.M.I. Ramadan, A.M. Ibrahim, Alexandria Eng. J. 55 (2016)

8. R.P. Roess, E.S. Prassas, W.R. McShane, Traffic engineering (Pearson Prentice Hall, New Jersey, 2004) 